\title{
The Effect of Dry-Land Quickness Training on Swimming Performance of 14-16 Ages Students
}

\section{Mine GUL ${ }^{1}$ \\ Semihcan AYDOGAN \\ Kocaeli University, Sports Science Faculty, Kocaeli, Izmit, Turkey. \\ Email:minegul7@gmail.com Tel: +905354144172 \\ Email: semih-aydogan@hotmail.com Tel: +905454332933}

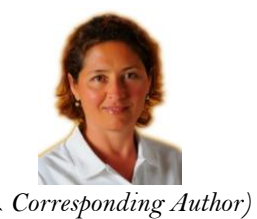

( Corresponding Author)

\begin{abstract}
This study aimed to research the effect of dry-land quickness training for 14-16 years old male swimmers on $50 \mathrm{~m}$ freestyle swimming performance. 30 volunteer male athletes and 10 volunteer males in the same age group who do not sport participated in this study. Athletes were grouped who took swimming training as experiment 1 (E1), experiment2 (E2) who took swimming \& quickness training and control (C) group who did not take an exercise. Zig-zag (ZZ), Square test (ST), Illinois test (IT), and T-test were applied for quickness skills; $50 \mathrm{~m}$ freestyle swimming degree was computed for the swimming performance before and after the training. Findings were discussed by applying paired sample T-test for in-group, independent samples T-test and One-Way ANOVA tests were applied for intergroup comparison. There are significant differences in all the measurement parameters based on pared sample T-test analysis results $(\mathrm{p}<0.05)$. Also, with reference to intergroup analysis that compared $\mathrm{E} 1, \mathrm{E} 2$, and $\mathrm{C}$ groups, there are significant differences in all the parameters $(\mathrm{p}<0.05)$ while there is no difference between E2 and $\mathrm{C}$ group in ZZ, ST, K, and IT measurement parameters $(\mathrm{p}>0.05)$. On the other hand, there is a significant difference at $50 \mathrm{~m}$ freestyle swimming degree. Exercise that were applied on dry-land as an addition to swimming training have an effect on quickness and swimming performance. It can be considered to be available method for swimmers to plan their training at the appropriate time.
\end{abstract}

Keywords: Swimming, Quickness, Exercise, Dry-land training, Performance, Strength.

Citation | Mine GUL; Semihcan AYDOGAN (2021). The Effect of Dry-Land Quickness Training on Swimming Performance of 14-16 Ages Students. Asian Journal of Education and Training, 7(1): 96102.

\section{History:}

Received: 22 January 2021

Revised: 24 February 202

Revised: 24 February 202

Accepted: 26 March 2021

Published: 29 April 2021
Licensed: This work is licensed under a Creative Commons Attribution 3.0 License $(\mathrm{cc}) \mathbf{E}$

Publisher: Asian Online Journal Publishing Group
Acknowledgement: Both authors contributed to the conception and design of the study.

Funding: This study received no specific financial support.

Competing Interests: The authors declare that they have no conflict of interests.

Transparency: The authors confirm that the manuscript is an honest, accurate, and transparent account of the study was reported; that no vital features of the study have been omitted; and that any discrepancies from the study as planned have been explained.

Ethical: This study follows all ethical practices during writing.

\section{Contents}

1. Introduction

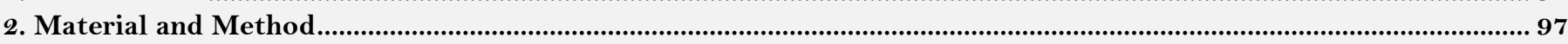

3. Results ......-.

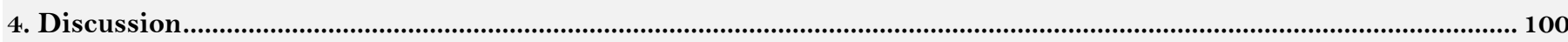

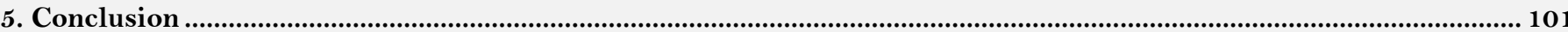

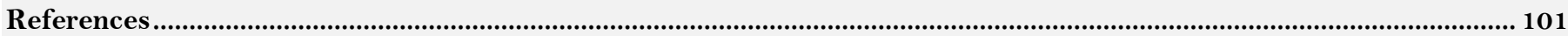




\section{Contribution of this paper to the literature}

It was aimed to investigate the effects of quick strength dry-land training, which is added to swimming training, on 50m freestyle swimming degree and quick strength performance. It can be said that quickness strength training organized according to age groups can have an effect on branch-specific performance development and can also help future research.

\section{Introduction}

Strength development varies by age groups. It is seen that there is a significant relationship between the content of the strength exercises for children and the strength development; there also are differences in strength development of girls and boys in some specific periods. The age variable plays a remarkable role in complex movements such as coordination. Males are at their best level for speed, hand-paw strength, throwing a med ball, agility, and jumping parameters after 9-years old. Therefore, it is an important issue to organize strength exercises so as to be proper to personal differences and periods of psychomotor development. So, trainers or coaches should be well-versed in the psychomotor development of children. It can also be mentioned that strength exercises that are consciously applied to children increase strength development. It is thought that water gymnastics, swimming and water sports help athletes in the development of physical and motoric properties and therefore will provide significant benefits in terms of the development of infrastructure athletes at the beginning stage (Adela, 2017; Deliceoğlu, 2015; Hekim \& Hekim, 2015).

Exercises that are planned fit for purpose in branches of sport and also coordination, strength, flexibility practices increase the agility and skills development (Karacabey, 2013). A well-structured and age-appropriate strength exercises program $(\mathrm{S} \& \mathrm{C})$ can be a valuable instrument to decrease the possibility of injury in young swimmers, improve movement skills and increase swimming performance. This is crucial for physical activity and providing long-term athlete participation in the sport. It is suggested to $\mathrm{S} \& \mathrm{C}$ coaches who work with young athletes to develop strong S\&C programs that are suited for the developmental and sport-specific needs of their athletes (Nugent, Comyns, \& Warrington, 2018). Studies on performance development have endeavored to reveal the importance of technology, equipment, and technical training (Smith, Norris, \& Hogg, 2002). It is also thought for coaches that attaching speed, quickness and skills exercises to strength and condition programs is a good method to improve explosive and elastic power besides speed-up and agility development (Jovanovic, Sporis, Omrcen, \& Fiorentini, 2011; Milanović, Sporiš, Trajković, James, \& Šamija, 2013). Besides the importance of performing all the movements at optimal speed; running technique, running speed, physical capacity and balance training are effective in providing agility development. Moreover, speed of movement, quick change of direction, and quick reaction in skill performed are also essential to provide quickness development (Sekulic, Spasic, Mirkov, Cavar, \& Sattler, 2013; Sheppard \& Young, 2006). Land exercises in swimming are the inseparable parts of programs of young ones, adolescents, and university students. It is highlighted that the relationship between swimming-specific movements and performance with anthropometric parameters (Ostrowska, Domaradzki, \& Ignasiak, 2011). As it becomes professional in exercises, there is a decline in land exercises; these related exercises are performed to reduce the risk of injury in specific periods of practice (Krabak, Hancock, \& Drake, 2013). It is thought that land exercises can increase the ability to generate propulsive forces in water for sprint swimmers. Moreover, conducting more studies to determine the appropriate volume and intensity of training programs according to gender and level will contribute to the performance (Morouço, Marinho, Amaro, Peréz-Turpin, \& Marques, 2012). It was mentioned in a study that there may be positive relations between maximum strength exercises and swimming performance (Aspenes \& Karlsen, 2012; Sadowski, Mastalerz, Gromisz, \& Niznikowski, 2012) leg repulsive muscles are effective in strength development (Cronnin, Jones, \& Frost, 2007). Again, with reference to findings of another research, coaches should encourage athletes for land exercises for the whole season; there will be seen an increase in pushing strength in water; improvement in arm drafting muscles; easiness in speed-up during diving; reduce friction in water and also keep the body position to strengthen core muscles (Dingley, Pyne, Youngson, \& Burkett, 2015).

\section{Material and Method \\ 2.1. Research Group}

30 volunteer male swimmers from 14-16 age club athletes in Üsküdar/İstanbul/Turkey Municipality participated in this study. Measurements were performed following the approval of the Ethics Committee and carried out in accordance with the Declaration of Helsinki. All testing and training procedures were fully explained, and written informed consent was obtained for each participant. Athletes continued to club swimming exercises for 8 weeks, so as to take 3 days a week for 60 minutes. Table 2 shows the descriptive data such as age, body weight, training age, arm span, and leg length. After the first measurements, athletes were randomly divided into two groups as Experiment 1 (E1) and Experiment2 (E2). Students who are not swimmers were specified as the Control (C) group. E1 group performed quickness exercises toward maximal speed beside club swimming exercises; E2 group performed club swimming exercises only.

\subsection{Research Method}

The most important characteristics of athletes are the ability to perform actions requiring maximum contraction, reaction time and rapid force in the shortest time and in the most number of times (Bompa, 2013; Bompa \& Haff, 2017). With the versatile foot drills, rapid change of direction and hip movements, it is aimed to improve the maximal strength level by using body weight while applying accelerated movements in both lower and upper extremities (Bayraktar, 2015). Quickness exercises Table 1 were performed toward maximal speed after 10 minutes-warm-up exercises on the land (4 different movements in each exercise) before club swimming exercises. The movements were applied as 3 sets of 4 repetitions and 1:1 rest from the first week. Scope of the exercises increased applying increasing repetition and sets. Quickness training was applied to improve the swimming performance of swimmers. It is aimed to be able to do the movements in a coordinated and faster. The quickness movements are designed in accordance with the purpose of the research. 
Table-1. Training moves

\begin{tabular}{l|l|l|l}
\hline 1 & Sequential stepping in the coordination ladder & 5 & One foot right left 20 bounces on the line \\
\hline 2 & Open and close foot in the coordination ladder & 6 & 5 cone in the middle cone go side by side go and come \\
\hline & $\begin{array}{l}\text { Double leg jumping right to left on the } \\
\text { coordination ladder }\end{array}$ & 7 & 20 high knee pulls \\
\hline 4 & Double foot bounce right left 20 times on the line & 8 & 5 meter shuttle run \\
\hline
\end{tabular}

\subsection{Data Collection}

Leg Length Measurement: The distance between the spina iliac anterior superior and the medial malleolus was measured with a tape measure while the athletes were in an upright position with their feet shoulder-width apart.

Arm Span Measurement: Measurements were taken with a tape measure while the athletes leaned against the wall, spread their arms to the side and parallel to the floor, and their hands were in contact with the dorsal wall.

Zig-Zag Test (ZT): A cone is placed in the center, leaving a distance of 4.86 meters on the long side of the cones and 3.04 meters on the short side. Departure and return directions were explained to the athletes. The time between the start and end of the test was measured with a stopwatch.

Square Test (ST): There was performed sprint from 1st to 2nd cone; side-by-side running from 2 nd cone to 3rd cone; back running from the 3rd to the 4th cone; sprint from the 4th to the 1 st cone. The time is recorded with the Stopwatch.

Cone Shuttle Test (CT): The athlete leans towards the ground and starts in a free position with one hand is on the ground and the other one is on the hip. The distance between the 1 st and 2 nd cones should be 4 meters 56.5 $\mathrm{cm}$. The distance between the 2 nd and $3 \mathrm{rd}$ cone should be 4 meters $56.5 \mathrm{~cm}$. The stopwatch is started with the start command. The athlete runs to the 1 st cone starting from the 1 st cone and turning from the back of the 2 nd cone. The time is stopped when he passes the 1st cone turning behind the 3rd cone.

Illinois Test (IT): The test track, consisting of three cones lined up on a straight line with $5 \mathrm{~m}$ width, $10 \mathrm{~m}$ length and $3.3 \mathrm{~m}$ intervals in the middle, was established in the gymnasium. The subjects exited from the starting line of the test track in the prone position and with their hands in contact with the ground at shoulder level. The time is stopped and recorded as the athlete crosses the finish line (Hazır, Mahir, \& Açıada, 2010).

T-Test (TT): Athletes touch the cones by performing A-B straight run, B-C side run, C-D side run, D-B horizontal run, and B-A back run in the "T" shape of the ABCD cones. Stopwatch starting at A is stopped at cone $\mathrm{A}$ again (The distance between the $\mathrm{A}$ and $\mathrm{B}$ cones was 9 meters and $35 \mathrm{~cm}$; the distance between the cones $\mathrm{B}$ and $\mathrm{C}$ was 4 meters $65 \mathrm{~cm}$; the distance between the cones B and D was 4 meters $65 \mathrm{~cm}$ ) (Haj-Sassi et al., 2011).

50 m Freestyle Swimming Degree (50m FSD): $50 \mathrm{~m}$ freestyle performance measurements of all subjects participating in the study were taken in a pool with a lane length of $25 \mathrm{~m}$. A stopwatch with an accuracy of $1 / 100$ second was used to record time in measurements.

\subsection{Analysis of Data}

For statistical calculations, SPSS 22.0 for windows was utilized to analyze the data; we preferred to study in a $95 \%$ confidence interval. The arithmetic mean $(\mathrm{X})$ and standard deviation $(\mathrm{SD})$ values for age, height, body weight, training age, stroke and leg length, ZT, ST, CT,IT,TT and 50m FSD first and last measurements of all athletes are presented in Table 2. The calculation of statistical significance between the pre-test and the post-test on the training targeted, apart from the difference of the arithmetic means of SD, the obtained data were determined to be suitable for normal distribution; parametric tests were applied then (Normality Test $p>0.05$ ). T-Test and One-Way ANOVA tests were applied for intergroup comparison. Paired Sample T-test analysis was utilized for in-group analyses. The threshold for significance was applied as $\mathrm{p}<.05$.

\section{Results}

Table-2. Descriptive statistics and measurement parameters analysis of research groups.

\begin{tabular}{|c|c|c|c|c|c|c|}
\hline \multirow[b]{2}{*}{ Parameters } & \multicolumn{2}{|c|}{$\mathrm{E} 1(\mathrm{n}=10)$} & \multicolumn{2}{|c|}{$\operatorname{E2}(n=10)$} & \multicolumn{2}{|c|}{$C(n=10)$} \\
\hline & $\operatorname{Mean}(\mathbf{X})$ & SD & $\operatorname{Mean}(\mathbf{X})$ & SD & $\operatorname{Mean}(\mathbf{X})$ & SD \\
\hline Age (year) & $15, \mathrm{OO}$ & 0,943 & 15,10 & 0,568 & 15,10 & 0,738 \\
\hline Heigh $(\mathrm{cm})$ & 175,710 & 5,223 & 176,030 & 3,110 & 172,970 & 3,961 \\
\hline Body Weigh (kg) & 63,550 & 5,334 & 68,570 & 6,522 & 68,590 & 5,126 \\
\hline Training Year (year) & 6,700 & 1,160 & 6,300 & 1,059 & 0,000 & 0,000 \\
\hline Stroke Length $(\mathrm{cm})$ & 175,690 & 5,160 & 176,580 & 3,487 & 173,130 & 4,678 \\
\hline Leg Length $(\mathrm{cm})$ & 96,500 & 5,426 & 96,750 & 3,600 & 93,600 & 4,648 \\
\hline ZT First & 8,940 & 0,369 & 9,260 & 0,986 & 9,853 & 0,979 \\
\hline ZT Last & 8,053 & 0,249 & 8,873 & 1,041 & 9,463 & 0,947 \\
\hline ST First & 5,789 & 0,360 & 6,620 & 0,528 & 6,586 & 0,556 \\
\hline ST Last & 5,303 & 0,252 & 6,200 & 0,547 & 6,209 & 0,517 \\
\hline CT First & 9,014 & 0,659 & 10,063 & 1,001 & 9,670 & 0,861 \\
\hline CT Last & 8,240 & 0,458 & 9,614 & 0,936 & 9,227 & 0,848 \\
\hline İT First & 11,056 & 0,662 & 11,884 & 0,827 & 12,060 & 0,847 \\
\hline İT Last & 9,989 & 0,550 & 11,563 & 0,860 & 11,588 & 0,902 \\
\hline TT First & 14,809 & 1,628 & 17,749 & 1,785 & 18,921 & 0,965 \\
\hline TT Last & 13,591 & 1,509 & 17,331 & 1,776 & 18,759 & 1,401 \\
\hline 50m FSD First & 31,620 & 1,161 & 32,142 & 1,187 & 45,912 & 3,396 \\
\hline $50 m$ FSD Last & 30,496 & 1,245 & 31,821 & 1,040 & 45,396 & 3,346 \\
\hline
\end{tabular}

Degree). 
As seen in Table 2 ; age, height, body weight, training age, arm and leg length descriptive statistics of E1, E2 and $\mathrm{C}$ groups were determined. The mean and standard deviation values of the first and last values of the measurement parameters are given in the table.

Table-3. First and last measurement analysis of measurement parameters of research groups.

\begin{tabular}{c|c|c|c|c|c|c|c|c|c|c|c|c}
\hline & \multicolumn{3}{|c|}{ E1 } & \multicolumn{3}{c|}{ E2 } & \multicolumn{3}{c}{ C } \\
\hline $\begin{array}{c}\text { First } \\
\text { Last }\end{array}$ & $\begin{array}{c}\text { Difference } \\
\text { Mean } \pm \text { SD }\end{array}$ & $\mathbf{t}$ & $\mathbf{r}$ & $\mathbf{p}$ & $\begin{array}{c}\text { Difference } \\
\text { Mean } \pm \text { SD }\end{array}$ & $\mathbf{t}$ & $\mathbf{r}$ & $\mathbf{p}$ & $\begin{array}{c}\text { Difference } \\
\text { Mean } \pm \text { SD }\end{array}$ & $\mathbf{t}$ & $\mathbf{r}$ & $\mathbf{p}$ \\
\hline ZT & $0,887 \pm 0,316$ & 8,878 & 0,534 & 0,112 & $0,387 \pm 0,217$ & 5,632 & 0,978 & $0,000^{*}$ & $0,390 \pm 0,149$ & 8,269 & 0,989 & $0,000^{*}$ \\
\hline ST & $0,486 \pm 0,181$ & 8,477 & 0,883 & $0,001^{*}$ & $0,420 \pm 0,147$ & 9,000 & 0,963 & $0,000^{*}$ & $0,377 \pm 0,092$ & 12,922 & 0,988 & $0,000^{*}$ \\
\hline CT & $0,774 \pm 0,371$ & 6,594 & 0,839 & $0,002^{*}$ & $0,449 \pm 0,141$ & 10,071 & 0,992 & $0,000^{*}$ & $0,443 \pm 0,144$ & 9,708 & 0,986 & $0,000^{*}$ \\
\hline İT & $1,067 \pm 0,332$ & 10,152 & 0,866 & $0,001^{*}$ & $0,321 \pm 0,123$ & 8,267 & 0,990 & $0,000^{*}$ & $0,472 \pm 0,126$ & 11,876 & 0,992 & $0,000^{*}$ \\
\hline TT & $1,218 \pm 1,065$ & 3,618 & 0,772 & $0,009^{*}$ & $0,418 \pm 0,211$ & 6,255 & 0,993 & $0,000^{*}$ & $0,162 \pm 0,700$ &, 731 & 0,889 & $0,001^{*}$ \\
\hline 50m & $1,124 \pm 0,221$ & 16,100 & 0,986 & $0,000^{*}$ & $0,321 \pm 0,207$ & 4,891 & 0,991 & $0,000^{*}$ & $0,516 \pm 0,312$ & 5,224 & 0,996 & $0,000^{*}$ \\
\hline
\end{tabular}

Note: $Z$ T=Zigzag Test;ST=Square Test;CT=Cone Test; $\mathrm{IT}=$ Illinois Test;TT=T Test;50m FSD=50 m Freestyle Swimming Degree.

Table-4. E1 and E2 groups measurement parameters analysis.

\begin{tabular}{|c|c|c|c|c|c|c|}
\hline Last Parameters & Group & Mean & SD & M.Dif. & $t$ & p \\
\hline \multirow{2}{*}{$\mathrm{ZT}$} & E1 & 8,053 & 0,249 & \multirow{2}{*}{$-0,820$} & \multirow{2}{*}{$-2,423$} & \multirow{2}{*}{$0,026^{*}$} \\
\hline & $\mathrm{E} 2$ & 8,873 & 1,041 & & & \\
\hline \multirow{2}{*}{ ST } & E1 & 5,303 & 0,252 & \multirow{2}{*}{$-0,897$} & \multirow{2}{*}{$-4,712$} & \multirow{2}{*}{$0,000^{*}$} \\
\hline & $\mathrm{E} 2$ & 6,200 & 0,547 & & & \\
\hline \multirow{2}{*}{ CT } & E1 & 8,240 & 0,458 & \multirow{2}{*}{$-1,374$} & \multirow{2}{*}{$-4,170$} & \multirow{2}{*}{$0,001 *$} \\
\hline & $\mathrm{E} 2$ & 9,614 & 0,936 & & & \\
\hline \multirow{2}{*}{ İT } & E1 & 9,989 & 0,550 & \multirow{2}{*}{$-1,574$} & \multirow{2}{*}{$-4,878$} & \multirow{2}{*}{$0,000^{*}$} \\
\hline & $\mathrm{E} 2$ & 11,563 & 0,860 & & & \\
\hline \multirow{2}{*}{ TT } & E1 & 13,591 & 1,509 & \multirow{2}{*}{$-3,740$} & \multirow{2}{*}{$-5,075$} & \multirow{2}{*}{$0,000^{*}$} \\
\hline & $\mathrm{E} 2$ & 17,331 & 1,776 & & & \\
\hline \multirow{2}{*}{$50 \mathrm{~m}$ FSD } & E1 & 30,496 & 1,245 & \multirow{2}{*}{$-1,325$} & \multirow{2}{*}{$-2,583$} & \multirow{2}{*}{$0,019 *$} \\
\hline & $\mathrm{E} 2$ & 31,821 & 1,040 & & & \\
\hline
\end{tabular}

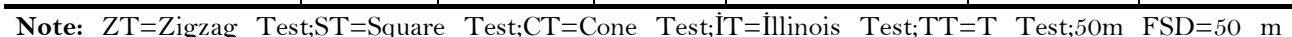

Freestyle Swimming Degree, ${ }^{*} \mathrm{p}<0.05$.

\begin{tabular}{|c|c|c|c|c|c|c|}
\hline Last Parameters & Groups & Mean & SD & M. Dif. & $t$ & p \\
\hline \multirow{2}{*}{$\mathrm{ZT}$} & $\mathrm{E} 1$ & 8,053 & 0,249 & \multirow{2}{*}{$-1,410$} & \multirow{2}{*}{$-4,552$} & \multirow{2}{*}{$0,000^{*}$} \\
\hline & $\mathrm{C}$ & 9,463 & 0,947 & & & \\
\hline \multirow{2}{*}{ ST } & E1 & 5,303 & 0,252 & \multirow{2}{*}{$-0,906$} & \multirow{2}{*}{$-4,986$} & \multirow{2}{*}{$0,000^{*}$} \\
\hline & $\mathrm{C}$ & 6,209 & 0,517 & & & \\
\hline \multirow{2}{*}{ CT } & E1 & 8,240 & 0,458 & \multirow{2}{*}{$-0,987$} & \multirow{2}{*}{$-3,240$} & \multirow{2}{*}{$0,005^{*}$} \\
\hline & $\mathrm{C}$ & 9,227 & 0,848 & & & \\
\hline \multirow{2}{*}{ İT } & E1 & 9,989 & 0,550 & \multirow{2}{*}{$-1,599$} & \multirow{2}{*}{$-4,785$} & \multirow{2}{*}{$0,000^{*}$} \\
\hline & $\mathrm{C}$ & 11,588 & 0,902 & & & \\
\hline \multirow{2}{*}{ TT } & $\mathrm{E} 1$ & 13,591 & 1,509 & \multirow{2}{*}{$-5,168$} & \multirow{2}{*}{$-7,936$} & \multirow{2}{*}{$0,000^{*}$} \\
\hline & $\mathrm{C}$ & 18,759 & 1,401 & & & \\
\hline \multirow{2}{*}{$50 \mathrm{~m}$ FSD } & $\mathrm{E} 1$ & 30,496 & 1,245 & \multirow{2}{*}{$-14,900$} & \multirow{2}{*}{$-13,197$} & \multirow{2}{*}{$0,000^{*}$} \\
\hline & $\mathrm{C}$ & 45,396 & 3,346 & & & \\
\hline
\end{tabular}

Note: ZT=Zigzag Test;ST=Square Test;CT=Cone Test;í: İllinois Test;TT=T Test;50m FSD=50 m Freestyle Swimming Degree.

Table-6. E2 and C groups measurement parameters analysis

\begin{tabular}{|c|c|c|c|c|c|c|}
\hline Last Parameters & Groups & Mean & SD & M. Dif. & $\mathrm{t}$ & p \\
\hline \multirow{2}{*}{$\mathrm{ZT}$} & $\mathrm{E} 2$ & 8,873 & 1,041 & \multirow{2}{*}{$-0,590$} & \multirow{2}{*}{$-1,326$} & \multirow{2}{*}{0,202} \\
\hline & $\mathrm{C}$ & 9,463 & 0,947 & & & \\
\hline \multirow{2}{*}{ ST } & $\mathrm{E} 2$ & 6,200 & 0,547 & \multirow{2}{*}{$-0,009$} & \multirow{2}{*}{$-0,038$} & \multirow{2}{*}{0,970} \\
\hline & $\mathrm{C}$ & 6,209 & 0,517 & & & \\
\hline \multirow{2}{*}{ CT } & $\mathrm{E} 2$ & 9,614 & 0,936 & \multirow{2}{*}{0,387} & \multirow{2}{*}{0,969} & \multirow{2}{*}{0,345} \\
\hline & $\mathrm{C}$ & 9,227 & 0,848 & & & \\
\hline \multirow{2}{*}{ İT } & $\mathrm{E} 2$ & 11,563 & 0,860 & \multirow{2}{*}{$-0,025$} & \multirow{2}{*}{$-0,063$} & \multirow{2}{*}{0,950} \\
\hline & $\mathrm{C}$ & 11,588 & 0,902 & & & \\
\hline \multirow{2}{*}{ TT } & $\mathrm{E} 2$ & 17,331 & 1,776 & \multirow{2}{*}{$-1,428$} & \multirow{2}{*}{$-1,996$} & \multirow{2}{*}{0,061} \\
\hline & $\mathrm{C}$ & 18,759 & 1,401 & & & \\
\hline \multirow{2}{*}{$50 \mathrm{~m}$ FSD } & $\mathrm{E} 2$ & 31,821 & 1,040 & \multirow{2}{*}{$-13,575$} & \multirow{2}{*}{$-12,250$} & \multirow{2}{*}{$0,000^{*}$} \\
\hline & $\mathrm{C}$ & 45,396 & 3,346 & & & \\
\hline
\end{tabular}

Note: $Z$ TT=Zigzag Test;ST=Square Test;CT=Cone Test;iT= $=$ Illinois Test;TT=T Test;50m FSD=50 m

Freestyle Swimming Degree * $(\mathrm{p}<0.05)$

As seen in Table 3, ZT first-last (E1: $r=0,534 ; p=0.112$ ( $p>0.05)$ / E2: $r=0,978 ; p=0.00 / C: r=0,989 ; p=0.00)$, ST first-last (E1: $r=0.883 ; \mathrm{p}=0.001 / \mathrm{E} 2: \mathrm{r}=0,963 ; \mathrm{p}=0.00 / \mathrm{C}: \mathrm{r}=0,988 ; \mathrm{p}=0.00)$, CT first-last $(\mathrm{E} 1: 0,839 ; \mathrm{p}=0.002 /$ E2: $r=0,992 ; p=0.00 / C: r=0,986 ; p=0.00)$, İT first-last (E1: r=0,866; $\mathrm{p}=0.001 / \mathrm{E} 2: \mathrm{r}=0,990 ; \mathrm{p}=0.00 / \mathrm{C}: \mathrm{r}=0,992$; $\mathrm{p}=0.00)$, TT first-last (E1: $\mathrm{r}=0,0772 ; \mathrm{p}=0.009 / \mathrm{E} 2: \mathrm{r}=0,993 ; \mathrm{p}=0.00 / \mathrm{C}: \mathrm{r}=0,889 ; \mathrm{p}=0.001)$ ve $50 \mathrm{~m}$ FSD first-last (E1: $r=0,986 ; p=0.00 / E 2: r=0,991 ; p=0.00 / C: r=0,996 ; p=0.00)$ significant differences were detected in the ingroup analyzes in the values. $(\mathrm{p}<0.05)$. 
As seen in Table 4, in the analysis of the measurement parameters, a significant difference was found in favor of the E1 group compared to the E2 group. (ZT: $p=0.026 ; \mathrm{ST}: \mathrm{p}=0.00 ; \mathrm{CT}: \mathrm{p}=0.001 ; \mathrm{IT}: \mathrm{p}=0.00 ; \mathrm{TT}: \mathrm{p}=0.00 ; 50 \mathrm{~m}$ FSD: $\mathrm{p}=0.019)(\mathrm{p}<0.05)$.

As seen in Table 5, in all of the last measurement values of the research parameters, a difference was determined in favor of the $\mathrm{E} 1$ group compared to the $\mathrm{C}$ group $(\mathrm{p}<0.05)$. Table 6: E2 And C Groups Measurement Parameters Analysis.

As seen in Table 6, E2 group differed from the C group in only 50m FSD (p <0.05). While the E2 group provided more improvement in terms of mean values in other parameters, there was no statistically significant difference $(\mathrm{p}>0.05)$.

\section{Discussion}

Effect of quickness exercises that were applied to 14-16-year-old male swimmers on the land on quickness performance and $50 \mathrm{~m}$ freestyle swimming performance was researched. Limitedness of this study consisted of 60 minutes-exercises for 3 days for 8 weeks. For the findings, the first measurement values before the exercises did not create the difference in analyses; values are homogeneous ( $p>0.05)$. There were quickness practices within club swimming exercises of the E1 group. E2 group performed swimming exercises only while the C group did not perform any sportive activities. Concerning the findings, the E1 group who performed quickness exercises made more different progress in terms of the average differences, first and last measurement compared to the $\mathrm{E} 2$ and $\mathrm{C}$ group Table 6. C group that performed swimming exercises only displayed significant differences in itself $(\mathrm{p}<0.05)$.

According to ZT measurements, there is significant difference in favor of E1 group based on the results of E1 and E2 groups (Mean Difference $=-0,820 ; \mathrm{t}=-2,423 ; \mathrm{p}=0,026)$ and $\mathrm{E} 1$ and $\mathrm{C}$ groups (Mean Difference=-1,410; $\mathrm{t}=-$ $4,552 ; \mathrm{p}=0,00)(\mathrm{p}<0.05)$. There was no significant difference between $\mathrm{E} 2$ and $\mathrm{C}$ groups (Mean Difference=-0,590; $\mathrm{t}=-1,326 ; \mathrm{p}=0,202)(\mathrm{p}>0.05)$; there was a difference in favor of E2 group. According to ST analyses, there was found significant differences in favor of E1 group based on E1 and E2 groups (Mean Difference=-O,897; $\mathrm{t}=-4,712$; $\mathrm{p}=0,00$ ) and $\mathrm{E} 1$ and $\mathrm{C}$ groups (Mean Difference=-0,906; $\mathrm{t}=-4,986 ; \mathrm{p}=0,00)$. A difference in favor of E2 group was observed at the end of swimming exercises while there was no significant difference between E2 and C groups (Mean Difference=-0,009; $\mathrm{t}=-0,038 ; \mathrm{p}=0,970)(\mathrm{p}>0.05)$. Regarding CT analyses, there were found significant differences in favor of $\mathrm{E} 1$ group based on the results of $\mathrm{E} 1$ and $\mathrm{E} 2$ groups (Mean Difference=-1,374; $\mathrm{t}=-4,17 \mathrm{O}$; $\mathrm{p}=0,001$ ) and $\mathrm{E} 1$ and $\mathrm{C}$ groups (Mean Difference=-0,987; $\mathrm{t}=-3,240 ; \mathrm{p}=0,005$ ). Again, a difference in favor of E2 group was observed at the end of swimming exercises while there was no significant difference between $\mathrm{E} 2$ and $\mathrm{C}$ groups (Mean Difference=0,387; $\mathrm{t}=0,969 ; \mathrm{p}=0,345)(\mathrm{p}>0.05)$.

Regarding IT analyses, there were found significant differences in favor of E1 group based on the results of E1 and E2 groups (Mean Difference $=-1,574 ; \mathrm{t}=-4,878 ; \mathrm{p}=0,00)$ and $\mathrm{E} 1$ and $\mathrm{C}$ groups (Mean Difference=-0,599; $\mathrm{t}=-$ $4,785 ; \mathrm{p}=0,00)$. A difference in favor of E2 group was observed at the end of swimming exercises while there was no significant difference between E2 and C groups (Mean Difference=-0,025; t=-0,063; p=0,950) ( $\mathrm{p}>0.05)$. With reference to TT analyses, there were significant differences in favor of E1 group based on the results of E1 and E2 groups (Mean Difference=-3,740; $\mathrm{t}=-5,075 ; \mathrm{p}=0,00$ ) and $\mathrm{E} 1$ and $\mathrm{C}$ groups (Mean Difference=-5,168; $\mathrm{t}=-7,936$; $\mathrm{p}=0,00)$. Again, there was observed a difference in favor of $\mathrm{E} 2$ group while there was no significant difference between E2 and C groups (Mean Difference=-1,428; $\mathrm{t}=-1,996 ; \mathrm{p}=0,61)(\mathrm{p}>0.05)$. Regarding 50m FSD analyses, there were found significant differences in favor of E1 group based on the results of E1 and E2 groups (Mean Difference $=-1,325 ; \mathrm{t}=-2,583 ; \mathrm{p}=0,00$ ) and $\mathrm{E} 1$ and $\mathrm{C}$ groups (Mean Difference $=-14,900 ; \mathrm{t}=-13,197 ; \mathrm{p}=0,00$ ). A significant difference in favor of $\mathrm{E} 2$ group from between $\mathrm{E} 2$ and $\mathrm{C}$ groups was observed (Mean Difference=-13,575; $\mathrm{t}=-12,250 ; \mathrm{p}=0,00)(\mathrm{p}<0.05)$.

Taşkın, Nurtekin, Dede, Amze, and Taşkın (2013) conducted a study on male and female swimmers with an average age of $11.50 \pm 1.60$ years and found that athletes who have high values of vertical jump are fast to turn in swimming. Girold et al. (2012) researched swimmers with an average age of $21.8 \pm 1.4$ years for 4 weeks. According to their findings, there was observed progress in both the group that performed land exercises and the electrical stimulation group $(p<0.05)$; however, there was no difference between the two groups $(p>0.05)$. They concluded that the 4-weeks exercise period fell short; programs that will take a long time will provide improvement. Sadowski et al. (2012) made a survey on male high school students with an average age of 15 to research the effect of strength exercises on flexibility, strength, and $50 \mathrm{~m}$ freestyle swimming performance. According to their results, there was seen progress in strength performance and swimming degree at the end of 6weeks land exercises while there was no statistical difference ( $p>0.05)$. Again, they mentioned that planning long exercises can increase swimming degree and flexibility at the same time.

Villareal, Arrones, Requena, Haff, and Veliz (2015) researched the effect of land exercises, pool exercises, and combined exercises for professional water-polo athletes with an average age of $23,4 \pm 4,1$. Exercises took 6 weeks so as to be 60 minutes for 3 days a week. There was found a difference $(p<0.05)$ in the strength parameter of the group who performed combined exercises when CMJ (Counter Movement Jump), splash, bench press, and full squat $1 \mathrm{RM}$, throwing speed (Ball), agility, and $20 \mathrm{~m}$ swimming degrees were reviewed. There also was observed a significant difference $(\mathrm{p}<0.05)$ in the first and last values of a splash, squat, and throwing speed of the group who performed exercises in water. Shah and Koley (2016) analyzed the effect of land and water exercises on the performance of elite swimmers aged 16-30. The relationship between performance and concentric and eccentric workouts lasting 3 days a week and 30 minutes for a total of 4 weeks. There was found a difference in the group who performed land exercises before and after the $50 \mathrm{~m}$ backstrokes $(34,73 \mathrm{~s} / 33,07 \mathrm{~s})$ and before and after $50 \mathrm{~m}$ freestyle swimming degree (27,21s / 25,92s).

Loturco et al. (2016) reviewed the effect of land and bound strength exercises on 50-100-200 m real-time swimming degrees for 10 well-trained 10 male athletes with an average age of $17.0 \pm 0.7$ years. They concluded that the relation between peak force and average force outcomes with the real swimming degrees is strong at shore distances (50m-100m). It is suggested to coaches to apply jumping exercises with loads and without loads to provide an increase in performance of the swimmers. Gül, Eskiyecek, Gül, and Karabulut (2019) 8-week swimming + Thera-band dry land training were evaluated, a significant improvement was observed in the measurement 
results between the control group and the experimental groups for 30 seconds push-up, 30 seconds sit-up, standing long jump and medicine ball toss, and there were a significant difference in all swimming degrees. It has been determined that land training applied to swimmers aged 11-13 has a positive effect on their swimming performance.

Garrido et al. (2010) reviewed the bench press, leg extension, throwing a medicine ball, and CMJ motor performance by applying strength exercises on the land for male and female swimmers with an average age of $12.08 \pm 0.7$ years. Exercises were performed for 8 weeks; 6 days a week for 90 minutes. With reference to research results, strength exercises are not a certain indicator for the increase in swimming performance. However, there may occur a development in sprint performance via these exercises. Amaro, Marinho, Marques, Batalha, and Morouço (2016) $12.7 \pm 0.7$ years of 21 male swimmers which applied for 10 weeks and the duration of the planned strength training, there was a significant difference $(p<0.05)$ in 50m swimming degree $(p=0.003)$.

Selçuk and Karacan (2017) researched the effect of Thera-band land exercises on the swimming performance of 11-13 years old male swimmers. Exercises took 5 days for 12 weeks. There were found significant differences $(p<0.05)$ in the swimming group and Thera-Band group. There also were found positive differences in favor of the subject group in terms of average values between the two groups. They concluded that resistance exercises on the land should be organized based on age groups by considering the positive changes in performance for Thera-Band exercises. Yapıcı, Maden, and Findıkoğlu (2016) researched the effect of land and resistance exercises on lower extremity isokinetic strength performance and swimming degrees for 13-16-year-old swimmers for 6 weeks; they found statistically significant differences in freestyle swimming degrees of $25 \mathrm{~m}-50 \mathrm{~m}-75 \mathrm{~m}-100 \mathrm{~m}$. There also was determined progress in the isokinetic strength performance of all the groups. They mentioned that related exercises positively affected the strength and swimming performances.

Sanioğlu, Turgut, Taşkın, Baloğlu, and Taşkın (2013) analyzed the relationship between agility and 10m-15m speed-up performance in male swimmers with an average age of $11.19 \pm 1.76$; there was a strong relationship in parameters $(r=0,843)$. They emphasized that designing annual training programs gain importance based on the growth and maturation process of the swimmer in exercises in which swimmers need agility and speed-up for quick turns, rapid strokes, and explosive jumps.

Aktuğ, Vural, and Ibis (2019) researched the effect of Thera band and swimming exercises on the motor performance and $50 \mathrm{~m}$ freestyle swimming degrees of boys and girls with an average age of $11.67 \pm 1.41$ years. They found that swimming exercises affect the swimming degrees; moreover, Thera band exercises on the land affect both motor performance and swimming degree. Sadowski et al. (2012) concluded that 6-weeks strength exercises have an impact on the $25 \mathrm{~m}$ freestyle swimming performance of swimmers with an average age of 14 (9,64\%) $(\mathrm{p}<0.05)$.

Senol and Gülmez (2017) reviewed the effect of functional exercises band (TRX) and resistance exercises on the swimming performance of 13-year-old licensed swimmers. There was observed progress in $200 \mathrm{~m}$ transition degrees (50m-100m-150m-200m) at the end of the measurements for the TRX group, body weight (resistance exercises) group, and the control group. There also were found statistically significant differences in 50m-150m and $200 m$ transition time $(\mathrm{p}<0.05)$. They expressed that TRX and resistance exercises were suggested to coaches to provide improvement in both physical and swimming performance.

Popovici and Suciu (2013) in their study on the effect of land training applied to children aged 11-12 for 4 weeks and 3 days a week on 50m butterfly style swimming degree, the authors found that athletes improved athletic performance and especially short distance swimming in water. Pe'rez-Olea, Valenzuela, Aponte, and Izquierdo (2018) in the study investigating the relationship between land strength training and swimming performance, lower extremity strength measurement $(\mathrm{CMJ})$ and the degree of free swimming were measured on the first day of performance swimmers aged 16-26, on the second day, swimmers' upper extremity and only leg only swimming degree were measured. As a result of this study, they found that upper extremity pull ups movements have a strong relationship with swimming performance and that it is an important issue that can be developed by coaches in dry land training.

\section{Conclusion}

This study revealed that agility and quickness skill tests and land exercises have positive effects on $50 \mathrm{~m}$ freestyle swimming performance. As a result of the literature research, it has been determined that dry land training has an effect on the development of some motoric properties, the development of flexibility values, the development of strength and the performance in the degrees of short distance swimming. It is suggested to coaches to make changes in loading intensity in each period of the exercise program by considering the developmental features of athletes.

\section{References}

Adela, B. (2017). Study of somatic motor and functional effects of practicing initiation programs in water gymnastics and swimming by students of physical education and sports. Physical Education of Students, 21(4), 158-164. Available at: http://dx.doi:10.15561/20755279.2017.0402.

Aktuğ, Z. B., Vural, Ş. N., \& Ibis, S. (2019). The effect of theraband exercises on motor performance and swimming degree of young swimmers. Turkish Journal of Sport and Exercise, 21(2), 238-243. Available at: 10.15314/tsed.578524.

Amaro, N. M., Marinho, D. A., Marques, M. C., Batalha, N. P., \& Morouço, P. G. (2016). Effects of dry land strength and conditioning programs in age group swimmers. Journal of Strength and Conditioning Research, 31(9), 2447-2454.

Aspenes, S. T., \& Karlsen, T. (2012). Exercise-training intervention studies in competitive swimming. Sports Medicine, 42(6), 527-543.

Bayraktar, I. (2015). Pliometric in different sports (3rd ed., pp. 17-82). Ankara: Epamat Publisher.

Bompa, T. O. (2013). Pliometric. Quickness training in sports (pp. 20-24). Ankara: Sport Publisher and Bookstore.

Bompa, T. O., \& Haff, G. G. (2017). Periodization, training theory and method (5th ed., pp. 293-295). Ankara: Sport Publisher and Bookstore.

Cronnin, J., Jones, J., \& Frost, D. (2007). The relationship between dry-land power measures and tumble turn velocity in elite swimmers. Journal of Swimming Research, $17(1), 17-23$.

Deliceoğlu, G. (2015). The motoric functions of children according to maturity coefficient. Turkiye Klinikleri Journal of Medicine Science, 35(1), 8-21. Available at: 10.5336/Medsci.2013-38482.

Dingley, A. A., Pyne, D. B., Youngson, J., \& Burkett, B. (2015). Effectiveness of a dry-land resistance training program on strength, power, and swimming performance in paralympic swimmers. Journal of Strength Conditioning Research, 29(3), 619-626. 
Garrido, N., Marinho, D. A., Reis, V. M., van den Tillaar, R., Costa, A. M., Silva, A. J., \& Marques, M. C. (2010). Does combined dry land strength and aerobic training inhibit performance of young competitive swimmers? Journal of Sports Science E Medicine, 9(2), 300310 .

Girold, S., Jalab, C., Bernard, O., Carette, P., Kemoun, G., \& Dugue' , B. (2012). Dry-land strength training vs. electrical stimulation in sprint swimming performance. Journal of Strength Conditioning Research, 26(2), 497-505.

Gül, M., Eskiyecek, C. G., Gül, G., \& Karabulut, P. (2019). The effect on in water and land thera-band studies on swimming performance. Sportive Sight: Journal of Sport and Education, 6(SI2), 420-431. Available at: https://doi.org/10.33468/sbsebd.117.

Haj-Sassi, R., Dardouri, W., Gharbi, Z., Chaouachi, A., Mansour, H., Rabhi, A., \& Mahfoudhi, M. E. (2011). Reliability and validity of a new repeated agility test as a measure of anaerobic and explosive power. Journal of Strength Conditioning Research, 25(2), 472-480. Available at: https://doi.org/10.1519/jsc.0bo13e3182018186.

Hazır, T., Mahir, O. F., \& Açıkada, C. (2010). Relationship between agility and body composition, anaerobic power in young soccer players. Hacettepe Journal of Sport Sciences, 21(4), 146-153.

Hekim, M., \& Hekim, H. (2015). Overview to strength development and strength trainings in children. The Journal of Current Pediatrics, 13, 110-115. Available at: 10.4274/jcp.22932.

Jovanovic, M., Sporis, G., Omrcen, D., \& Fiorentini, F. (2011). Effects of speed, agility, quickness training method on power performance in elite soccer players. The Journal of Strength $\mathcal{E}^{\circ}$ Conditioning Research, 25(5), 1285-1292. Available at: https://doi.org/10.1519/jsc.0bo13e3181d67c65.

Karacabey, K. (2013). Sport performance and agility tests. Journal of Human Sciences, 1O(1), 1693-1704.

Krabak, B. J., Hancock, K. J., \& Drake, S. (2013). Comparison of dry-land training programs between age groups of swimmers. American Academy of Physical Medicine and Rehabilitation, 5(4), 303-309. Available at: http://dx.doi.org/10.1016/j.pmrj.2012.11.0033.

Loturco, I., Barbosa, A. C., Nocentini, R. K., Kobal, R., Kitamura, K., Abad, C. C. C., . . Nakamura, F. Y. (2016). A correlational analysis of tethered swimming, swim sprint performance and dry-land power assessments. International Journal of Sports Medicine, 37, $211-218$. Available at: http://dx.doi.org/10.1055/s-0035-1559694.

Milanović, Z., Sporiš, G., Trajković, N., James, N., \& Šamija, K. (2013). Effects of a 12 week saq training programme on agility with and without the ball among young soccer players. Journal of Sports Science \& Medicine, 12(1), 97-103.

Morouço, P. G., Marinho, D. A., Amaro, N. M., Peréz-Turpin, J. A., \& Marques, M. C. (2012). Effects of dry-land strength training on swimming performance: A brief review. Journal of Human Sport and Exercise, 7(2), 553-559. Available at: 10.4100/jhse.2012.72.18.

Nugent, F. J., Comyns, T. M., \& Warrington, G. D. (2018). Strength and conditioning considerations for youth swimmers. National Strength and Conditioning Association, Strength and Conditioning Journal, 4O(2), 31-39. Available at: https://doi.org/10.1519/ssc.0000000000000368.

Ostrowska, B., Domaradzki, J., \& Ignasiak, Z. (2011). Factor analysis of anthropometric characteristics in young swimmers aged 11 and 12. Applications of Mathematics Gymnica, 36(1), 59-68.

Pe'rez-Olea, J. I., Valenzuela, P. L., Aponte, C., \& Izquierdo, M. (2018). Relationship between dryland strength and swimming performance: Pull-up mechanics as a predictor of swimming speed. Journal of Strength Conditioning Research, 32(6), 1637-1642.

Popovici, C., \& Suciu, M. A. (2013). Dry land training and swimming performance in children aged 11-12 years. Palestrica of the Third Millennium Civilization E Sport, 14(3), $219-222$.

Sadowski, J., Mastalerz, A., Gromisz, W., \& Niznikowski, T. (2012). Effectiveness of the power dry-Land training programme in youth swimmers. Journal of Human Kinetics, 32, 77-86. Available at: 10.2478/v 10078-012-0025-5.

Sanioğlu, A., Turgut, K., Taşkın, H., Baloğlu, G., \& Taşkın, C. (2013). Relatiıonships between quickness, agility, and acceleration performance in boy swimmers. Science, Movement and Health, 13(2), 325-329.

Sekulic, D., Spasic, M., Mirkov, D., Cavar, M., \& Sattler, T. (2013). Gender-specific influences of balance, speed, and power on agility

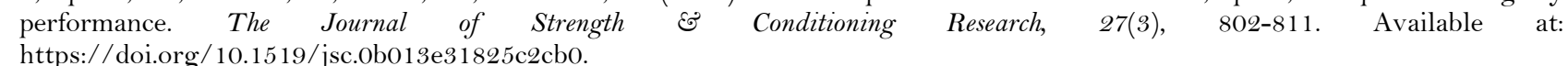

Selçuk, H., \& Karacan, S. (2017). The effects of 12-weeks thera-band training on swimming performance at 11-13 age group swimmers. Journal of Human Sciences, 14(4), 4958-4968. Available at: 10.14687/jhs.v 14i4.4858.

Senol, M., \& Gülmez, I. (2017). Effects of functional exercise band (trx) and body weight resistance training on swimming performance. Istanbul University Journal of Sport Science, 7(1), 62-75.

Shah, P. K., \& Koley, S. (2016). Swimmer's shoulder in athletes: Comparison between efficacy of aquatic versus dry-land concentric-eccentric exercises. Human Biology Review, 5(2), 168-175.

Sheppard, J. M., \& Young, W. B. (2006). Agility literature review: Classifications, training and testing. Journal of Sports Sciences, 24(9), 919932. Available at: 10.1080/02640410500457109.

Smith, D., Norris, S., \& Hogg, J. M. (2002). Performance evaluation of swimmers. Sports Medicine, 32(9), 539-554.

Taşkın, H., Nurtekin, E., Dede, B., Amze, G., \& Taşkın, M. (2013). Effect of vertical jump on quickness, agility, acceleration and speed performance in children swimmer. Science, Movement and Health, 13(2), 347-351.

Villareal, S. E., Arrones, L. S., Requena, B., Haff, G. G., \& Veliz, R. R. (2015). Enhancing performance in Professional water polo players: Dryland training, in-water training, and combined training. Journal of Strength Conditioning Research, 29(4), 1089-1097.

Yapıcı, A., Maden, B., \& Findıkoğlu, G. (2016). The effect of a 6-week land and resistance training of 13-16 years old swimmers groups to lower limb isokinetic strength values and to swimming performance. Journal of Human Sciences, 13(3), 5269-5281. Available at: $10.14687 /$ jhs.v 13 i3.4158. 